\title{
The Unintended Consequences of Social Media in Healthcare: New Problems and New Solutions
}

\author{
S. Hors-Fraile', S. Atique ${ }^{2}$, M. A. Mayer ${ }^{3}$, K. Denecke ${ }^{4}$, M. Merolli ${ }^{5}$, M. Househ ${ }^{6}$ \\ 1 Department of Computer Technology and Architecture, University of Seville, Seville, Spain \\ 2 Graduate Institute of Biomedical Informatics, Taipei Medical University, Taipei, Taiwan \\ ${ }^{3}$ Research Programme on Biomedical Informatics (GRIB), IMIM-Universitat Pompeu Fabra, \\ Barcelona, Spain \\ 4 Institute for Medical Informatics, Bern University of Applied Sciences, Bern, Switzerland \\ ${ }^{5}$ Health and Biomedical Informatics Centre, The University of Melbourne, Victoria, Australia \\ 6 King Saud Bin Abdulaziz University for Health Sciences, College of Public Health and Health \\ Informatics, Ministry of National Guard Health Affairs, Riyadh, Kingdom of Saudi Arabia
}

\begin{abstract}
Summary
Objectives: Social media is increasingly being used in conjunction with health information technology (health IT). The objective of this paper is to identify some of the undesirable outcomes that arise from this integration and to suggest solutions to these problems.

Methodology: After a discussion with experts to elicit the topics that should be included in the survey, we performed a narrative review based on recent literature and interviewed multidisciplinary experts from different areas. In each case, we identified and analyzed the unintended effects of social media in health IT. Results: Each analyzed topic provided a different set of unintended consequences. Most relevant consequences include lack of privacy with ethical and legal issues, patient confusion in disease management, poor information accuracy in crowdsourcing, unclear responsibilities, misleading and biased information in the prevention and detection of epidemics, and demotivation in gamified health solutions with social components.

Conclusions: Using social media in healthcare offers several benefits, but it is not exempt of potential problems, and not all of these problems have clear solutions. We recommend careful design of digital systems in order to minimize patient's feelings of demotivation and frustration and we recommend following specific guidelines that should be created by all stakeholders in the healthcare ecosystem.
\end{abstract}

\section{Keywords}

Social media, gamification, epidemics, chronic disease, outcomes, ethics, legal, crowdsourcing

Yearb Med Inform 2016:47-52 http://dx.doi.org/10.15265//Y-2016-009

Published online November 10, 2016

\section{Introduction}

At the end of 2015, the average social network penetration rate worldwide was estimated to be $29 \%$ [1]. Approximately 2 billion Internet users from around the world are using social media (SM), and although the use of social networks varies among countries, people worldwide are engaged in these technologies and actively use them [2].

The latest developments in health information technology (IT) and the increased acceptability of SM in health are leading to IT solutions that combine both tools. This integration of SM with IT-based health solutions provides several benefits to society. In chronic disease management, SM offers advantages such as increased psychological well-being, social health, and cognitive health [3]. SM data itself may be used in protecting citizens from public health threats or as a means of communication during epidemics [4-5]. This may help improving notification times and make firsthand information available to the public. When SM is combined with gamification techniques to help patients have a healthier lifestyle, their engagement and motivation is potentially increased [6]. SM is also one of the main pillars of crowdsourcing. It allows patients to seek multiple opinions from an online crowd, which could help inform them about their treatment or diagnosis options. Previous studies have shown that crowds can offer better advice than single individuals and, at times, can provide more accurate opinions than educated professionals [7-9].

Nevertheless, despite these potential benefits, the challenges of these new opportunities may result in negative outcomes if not addressed properly. For instance, YouTube can be used to spread anorexia-related misinformation, tobacco promotion, and public exhibitions of unhealthy behavior [10-11]. In this study, we do not intend to provide a comprehensive analysis of the issue, but the aim is to provide an overview of some of the potential unintended consequences of SM and health IT.

\section{Methods}

Over the course of five days, all members of the IMIA Social Media Working Group (SMWG), who agreed to participate in this study, discussed their own experience in order to elicit the topics to be explored. The authors agreed to include ethical and legal considerations, the prevention and detection of epidemics, chronic disease management, crowdsourcing, and gamified health solutions. These topics were divided into two groups: "Healthcare professionals and other stakeholders" included the first two topics and "Patients as stakeholders" the later three.

Since this study was intended to be exploratory rather than comprehensive, the authors chose different approaches and 
sources for each topic. Three of the topics were analyzed using a literature review, as summarized in Table 1.

The topic of the prevention and detection of epidemics was explored by collecting experiences of the authors in the development and testing phase of the M-Eco system [5], a surveillance system that analyses Twitter and other SM data for the purpose of detecting public health threats. Further, we summarized the relevant ethical, legal, and social implications discussed at the DELSI (Digital Epidemiology and its ethical, Legal and Social Implications) International Symposium [12], where epidemiologists, sociologists, lawyers, and computer scientists discussed the implications of digital epidemiology.

With regard to the topic of patient use of health crowdsourcing platforms, the authors combined their own experiences with literature from PubMed and Forbes Magazine online.

Table 1 Summary of the literature reviews conducted for the topics "Ethical and legal considerations", "Chronic disease management", and "Gamified health solutions with social components".

\begin{tabular}{|c|c|c|c|c|}
\hline & Keywords & Databases & Unfiltered hits & $\begin{array}{l}\text { Final results } \\
\text { (non-duplicated, } \\
\text { and relevant) }\end{array}$ \\
\hline $\begin{array}{l}\text { Ethical } \\
\text { and legal } \\
\text { considerations }\end{array}$ & $\begin{array}{l}\text { "SM," "web 2.0," "ethics," } \\
\text { "ethical," "legal," "legislation," } \\
\text { "professionalism", "medical } \\
\text { doctors", "guidelines", } \\
\text { "recommendations" }\end{array}$ & $\begin{array}{l}\text { PubMed, } \\
\text { Google }\end{array}$ & $\begin{array}{l}588 \text { returns (we took } \\
\text { the first } 150 \text { from } \\
\text { Google, and the rest } \\
\text { from PubMed) }\end{array}$ & 28 papers \\
\hline $\begin{array}{l}\text { Chronic disease } \\
\text { management* }\end{array}$ & $\begin{array}{l}\text { "social media," "chronic disease," } \\
\text { "chronic illness," combined with: } \\
\text { "fear," "misrepresent," "mislead," } \\
\text { "misinform," "dangerouss," } \\
\text { "disreputable," "withdrawal," } \\
\text { "frustration," "confusion," } \\
\text { "uncertainty," "distress," } \\
\text { "dejection," "isolation," } \\
\text { "alienation," "catastrophism," } \\
\text { "desperation" }\end{array}$ & $\begin{array}{l}\text { PubMed, Web of } \\
\text { Science, Scopus, } \\
\text { Computers and } \\
\text { Applied Sciences }\end{array}$ & 14 returns & 4 papers \\
\hline $\begin{array}{l}\text { Gamified } \\
\text { health solutions } \\
\text { with social } \\
\text { components }\end{array}$ & "gamification," "social," "health." & $\begin{array}{l}\text { PubMed, PsycNet, } \\
\text { IEEE and ACM. }\end{array}$ & $\begin{array}{l}100 \text { returns (we took } \\
\text { the first } 43 \text { - sorted } \\
\text { by higher relevance } \\
\text { - from ACM, and } \\
\text { the rest from the other } \\
\text { databases) }\end{array}$ & 7 papers \\
\hline
\end{tabular}

* keywords used for unintended negative consequences in the literature search were adopted from a global online survey of SM use in managing chronic disease (i.e., chronic pain) [10].

\section{Results}

\subsection{Healthcare Professionals and Other Stakeholders}

\section{Ethical and Legal Considerations when Using Social Media for Health Purposes}

The incorporation of SM in daily health care activities should be accompanied by the development of measures to ensure their safe use guaranteeing medical professionalism and ethical and legal requirements, especially when using open and massive online services [13]. Several guidelines and recommendations for good practices were developed to highlight the most important aspects for the use of SM for health purposes as well as descriptions of their advantages and drawbacks [14-18].

The use of SM tools has led to innovations in health care that have generated issues and left unanswered legal and ethical questions.

The use of SM has led to unexpected drawbacks and challenges regarding the protection of personal data, particularly in the case of sensitive data such as health information.

Taking into account that connections with other users result in making content accessible to anyone connected to the Internet, risks related to misinformation, privacy, and confidentiality, and the right to be forgotten are the main concerns when posting and participating in SM. In addition, the use of sophisticated and automatic tools for collecting and monitoring personal data and behavior has become increasingly common and less detectable. Studies have suggested that unprofessional uses of SM are frequent among health professionals and various improper behaviors, such as violations of patient privacy, posting sexually suggestive photos, defamation and criticism of others, and racist content online are among the most common problems detected on these platforms [17, 20-25].

SM tools are in the process of being widely adopted in health care services, and it is common for laws and ethical guidelines to lag behind new technical developments. Thus, it is essential to urgently fill the gap among policy makers and healthcare professionals. It is also important that the relevant authorities and governments apply ethical and legal guidelines related to the use of SM tools for health communication [26]. This should be done in collaboration with patient associations and professional institutions to establish specific policies that benefit to healthcare professional-patient relationship and the general public.

\section{Social Media Use for the Prevention and Detection of Epidemics}

Scientific assessments of the utility of SM web mining in the domain of public health have shown that such use could help in overcoming time delays in reacting to health threats, e.g. by providing additional information about outbreaks [27]. However, while beneficial, the use of SM to detect epidemics can lead to some undesirable or unintended consequences with regard to technical, functional, and formal issues. Although it is still unclear how reliable the content collected from SM is to detect public health threats, it is technically possible to do it as multiple 
projects have shown [4] [5] [9]. Legal issues include the responsibilities of public health officials when using SM for epidemiological purposes since through social media, personal data from individuals that usually remains unknown to health officials at a national level becomes available. We were unable to identify any guidelines for health organizations using SM to detect public health threats. It is unclear how they should react when they identify a group of sick persons based on their SM discussions: are these organizations allowed to react to or act on this information?

Technical and functional challenges exist related to data volume and there is an increased risk of generating false alarms. Although SM data provides a new source of information regarding public health threats, its analysis and interpretation are challenging. The ambiguity of language makes automatic interpretation difficult: for example, symptoms can be used in other contexts than expected (e.g., "football fever" could produce an alert since the keyword "fever" is used). Such ambiguity could create an additional undesirable workload for epidemiologists due to the a priori large numbers of such false alarms.

Another issue is the quality and reliability of the data as well as the localization of outbreaks. As reported by Goff et al. [7], misinformation regarding infectious diseases is sometimes disseminated through Twitter. The majority of SM users are young people originating from the more developed countries making SM-based information biased and open to the spread of misleading information, as reported by Paul et al. [9]. Dyar et al. [8] found out that Twitter leads to the promotion of some searches and the sharing of information about outbreaks globally rather than locally. This can become misleading as an outbreak can occur in a certain part of the world while information about it is being shared in other parts (e.g. Zika virus).

\subsection{Patients as Stakeholders}

\section{SM Use May Lead to Negative Patient Emotions}

Some of the positive health outcomes reported from SM use include improvements on psychological well-being, social health, and cognitive health [28-31]. However, despite the observed largely positive patient-reported outcomes (PROs), unintended consequences can sometimes arise from SM-based self-managed support, such as apprehension, frustration, confusion, or dejection.

Apprehension surrounding personal identity disclosure in online environments can manifest from fear of the unknown to concerns of inadvertent interactions with people masquerading as an illness peer [32]. Regarding personal identification, Nordfeldt et al. [33] suggested that the use of SM can not only increase sensations of stigmatization, but it may also create an identity centered on a patient's disease. This was echoed by Pousti and Burstein [34], who suggested that the use of SM might have a role in self-esteem lowering.

Feelings of frustration have been suggested by Nordfeldt et al. [33]. They reported that when a search fails to retrieve up-to-date relevant information in a timely manner, it can be extremely frustrating to SM users. However, the primary negative consequence attributed to SM use is quite possibly confusion. The studies examined by the authors indicated that SM users may be left feeling confused when an online search returns conflicting information [33] [35]. According to Zebrack and Isaacson [35], this may have a negative impact on an individual's ability to successfully evaluate information and distinguish potentially useful and helpful information from irrelevant and misleading information. According to Nordfeldt et al. [33], confusion is also one of the main reasons for health-related SM use attrition.

The positive impact of sharing one's experiences through SM has been reported in the light of the emotionally cathartic effect it has on SM users [32]. However, it has also been observed that certain negative outcomes can arise in conjunction with the generally positive perception of the narrative effect that SM enables. Findings by Merolli et al. [32] highlighted instances of patient comments that include distress, dejection, isolation, alienation, catastrophizing, and desperation related to sharing experiences with others. This suggests that communicating about one's experiences with illness may have a potentially negatively impact. Pousti and Burstein [34] proposed the term "emo- tional discomfort" to label this sensation. However, there were few such reports in the articles in our analysis, and the emotional impact of sharing experiences was described as largely positive.

\section{Patient Use of Crowdsourcing Platforms: the Power and Limitation of Crowds}

Crowdsourcing allows patients to seek opinions from an online crowd, which can help inform their diagnosis or treatment options. Although concerns arise with fraudulent patients seeking out financial and emotional support from the online community, previous studies have shown that crowds may offer more informed advice than single individuals can, and at times, crowds can provide more accurate opinions than can educated professionals [36-38]. Crowdsourcing can also help uninsured patients in the United States raise funds to pay their medical bills. For instance, one patient raised $\$ 41,032$ to cover the expenses of cancer treatment; this patient's friends shared the campaign information using Facebook and e-mail. Another patient's campaign was shared on both Facebook and Twitter, and resulted in the raising of more than $\$ 50,000$ [39]. However, there are some unintended consequences of crowdsourcing for healthcare, e.g. the accuracy of crowd's diagnoses, the use of trusted health crowdsourcing platforms, and the privacy and confidentiality related to the sharing of health information online.

Crowdsourcing proponents state that crowdsourcing leads to knowledge discovery and can help solve real problems. The process is collaborative and involves people from different disciplines, which allows for innovation [40]. Despite these promises, our search of the evidence did not find research claims justifying the accuracy of the diagnoses and treatments established when using online crowdsourcing systems. Patients currently use health crowdsourcing platforms as an alternative to professional medical advice, which may cause them more harm than benefits. Without proper evidence, more research is needed to test health crowdsourcing platforms for this use.

Specific to crowdsourcing, there are privacy and confidentiality issues that arise when patients begin to use these kinds of platforms. One of the issues noted by De- 
necke et al. is the inability for any legislation to regulate the online sharing of personal health information by patients. The current legislation in European and North American countries only prevents patients' healthcare information from being shared by providers and institutions. Patients themselves are free to share their personal information [41].

\section{Gamified Health Solutions with Social Com-} ponents: Lessons Learned for their Design

Most gamified health and fitness apps may either have pre-set goals or they let users set their own. For people with special needs, it may be risky to let them follow an app's instructions on their own. If such users receive incorrect training from an app, this may cause injuries or lead to poor performance [42]. To mitigate this risk, healthcare professionals should first approve the goals of gamified health apps according to each person's special health needs.

The social component in competitive gamified health systems may be a strong motivator. This differs from games because games are designed to be played, while gamified systems are meant to be used. When a gamified system is going to be implemented, it is crucial to set limits for those who want to "play the system". It is indeed necessary to establish barriers in order to avoid that people forget for what the system was designed. Otherwise, people may lose track of their initial goal of getting healthier, as was reported by Yeoreum Lee et al. [43]. To solve this issue, we should introduce safeguards that stop people from playing the system. Other types of non-social incentives could be introduced to contribute to these types of personal improvements.

In some gamified systems, patients have to input or track their health data, which may be emotionally charged. If they think their health is trivialized in a game, or if they do not manage to reach their game goals and feel judged by others in the social game, they are likely to abandon it. Ancker suggested [44] that to avoid this, it is beneficial to have fewer game elements and simply retrieve the necessary health data. Pure data tracking will not trigger negative emotions. Another option is to set variable privacy settings, so that each person decides how much and what part of their personal health data they want to share [45]. Comparison is also an important issue when competing in teams. In two gamified family-focused collaborative health app studies [46] [47], parents complained about the possibility that their children may become demotivated if other families ranked better than theirs did. The extensive usage of gamification creates a tolerance to it. This may negatively impact other non-gamified systems because users will need gamification to become engaged with the system, as Walthouwer reported [48].

Table 3 displays the summary of the unintended consequences of SM and health IT for patients as stakeholders.

\section{Conclusions}

\subsection{Healthcare Professionals and Other Stakeholders}

The use of SM tools for health purposes generates several problems and unanswered legal and ethical questions. Although SM can provide many benefits and opportunities, as previously mentioned, its main legal and ethical concerns rely on the risks related to misinformation and maintaining privacy, confidentiality, and the right to be forgotten. Thus, it is necessary that authorities and governments establish, in collaboration with patients associations and professional institutions, specific guidelines and policies to assist health professionals and help Internet users benefit from the use of SM for health.

The use of SM data has also proven to be useful in monitoring public health and in detecting health threats, such as epidemics. To effectively introduce it in health systems, IT professionals need to create the conditions to sufficiently filter the data, and authorities and epidemiologists need to create the rules and guidelines describing how to react to the signals generated to avoid unintended consequences.

\subsection{Patients as Stakeholders}

Regarding PROs from SM use within a chronic disease management context, one worthwhile discussion focuses on the relatively small number of studies on the potential negative consequences of SM use (four in total in our analysis). Future SM use in chronic disease research is necessary to address patient-reported issues such as confusion and frustration regarding online information and the need to find up-to-date information in a timely manner. This could have a positive impact on improving the eHealth literacy of the online health consum-

Table 3 Summary of the unintended consequences of health social media for patients as stakeholders.

\begin{tabular}{|c|c|c|c|}
\hline & \multicolumn{3}{|c|}{ Patients as stakeholders } \\
\hline & Chronic disease management & Crowdsourcing & $\begin{array}{l}\text { Gamified health solutions with } \\
\text { SM components }\end{array}$ \\
\hline $\begin{array}{l}\text { Unintended } \\
\text { consequences }\end{array}$ & $\begin{array}{l}\text { - Being deceived by someone } \\
\text { claiming to be someone else. } \\
\text { - Creation of an identity around the } \\
\text { disease. } \\
\text { - Confusion in distinguishing } \\
\text { useful from harmful or irrelevant } \\
\text { information. } \\
\text { - Insecurity about how to introduce } \\
\text { oneself online and in trusting } \\
\text { others. } \\
\text { - Distress, dejection, isolation, } \\
\text { alienation, catastrophizing, } \\
\text { and desperation when sharing } \\
\text { experiences with illness online. }\end{array}$ & $\begin{array}{l}\text { - Limitation regarding accu- } \\
\text { racy of crowd diagnoses. } \\
\text { - Privacy and sharing confi- } \\
\text { dential health information } \\
\text { online. } \\
\text { - Manipulation of vulnerable } \\
\text { patients. } \\
\text { - Use of trusted health } \\
\text { crowdsourcing plafforms. }\end{array}$ & $\begin{array}{l}\text { - Gamified preset goals do not } \\
\text { meet patients' health needs. } \\
\text { - Lack of barriers to prevent } \\
\text { cheating. } \\
\text { - Patients' tolerance to } \\
\text { gamification affecting non- } \\
\text { gamified systems. } \\
\text { - Patients forget the health aim of } \\
\text { the system and "play it" instead. } \\
\text { - Patient demotivation and low } \\
\text { adherence if they do not win, do } \\
\text { not reach their own goals, feel } \\
\text { judged, or feel their health is } \\
\text { trivialized. }\end{array}$ \\
\hline
\end{tabular}


ing public. The consequences of patients' narcissism derived from SM use are worthy of consideration for future research.

Crowdsourcing in healthcare provides patients with the power to harness the knowledge of crowds, and it can result in diagnosis and treatment options, but there remains a multitude of challenges, as previously described. To solve these, we propose the use of trusted health crowdsourcing platforms to provide medical advice to patients, especially vulnerable patients with rare diseases. Vulnerable patients are at risk of being manipulated by unscrupulous health crowdsourcing platforms promising to help them find diagnoses or treatments for medical conditions. Trusted platforms are needed to allow patients to seek medical advice from real patients and healthcare professionals. Mechanisms are needed, such as the HON Code Foundation, to verify trusted health crowdsourcing platforms.

As we saw in section 3, most of the problems concerning gamification and SM may be overcome through proper design. Having healthcare professionals tailor the gamified goals for each patient is highly recommended. Unfortunately, there currently exist no health-specific gamification frameworks, and we encourage future research on this issue.

\section{Limitations}

The topics discussed were selected by the members of the IMIA SMWG, and their selection may have been biased by members' areas of expertise. Therefore, other relevant topics may have been overlooked in this study. In addition, the aim of this paper was not to conduct an exhaustive review of each topic, but rather the aim was to present an exploratory synthesis of the existing studies and reviews. Thus, deeper research using a homogeneous and systematic methodology is recommended for each topic.

\section{Acknowledgments}

We thank Margaret Hansen from the University of San Francisco and Elia Gabarron from the Norwegian Center for E-health Research for their input and kind support reviewing this manuscript.

\section{References}

1. Statista [Internet]. [Place unknown]: [publisher unknown]; March 2016 [cited March 27 2016] Available from: http://www.statista.com/statistics/433871/daily-social-media-usage-worldwide/

2. Statista [Internet]. [Place unknown]: [publisher unknown]; September 2015 [cited March 27 2016] Available from: http://www.statista.com/ statistics/454799/social-media-hours-region/

3. Stellefson M, Chaney B, Barry AE, Chavarria E, Tennant B, Walsh-Childers K, et al. Web 2.0 chronic disease self-management for older adults: a systematic review. J Med Internet Res 2013;15(2)

4. Velasco E, Agheneza T, Denecke K, Kirchner G, Eckmanns T. Social media and internet-based data in global systems for public health surveillance: a systematic review. Milbank Q 2014 Mar;92(1):7-33.

5. Denecke K, Krieck M, Otrusina L, Smrz P, Dolog P, Nejdl W, et al. How to exploit twitter for public health monitoring? Methods Inf Med 2013;52(4):326-39

6. Allam A, Kostova Z, Nakamoto K, Schulz PJ. The Effect of Social Support Features and Gamification on a Web-Based Intervention for Rheumatoid Arthritis Patients: Randomized Controlled Trial. J Med Internet Res 2015;17(1):e14

7. Goff DA, Kullar R, Newland JG. Review of twitter for infectious diseases clinicians: useful or a waste of time? Clin Infect Dis 2015;60(10):1533-40.

8. Dyar OJ, Castro-Sánchez E, Holmes AH. What makes people talk about antibiotics on social media? A retrospective analysis of Twitter use. J Antimicrob Chemother 2015;69(9):2568-72.

9. Paul MJ, Dredze M. You are what you Tweet: Analyzing Twitter for public health. In ICWSM 2011:265-72.

10. Bermúdez-Tamayo C, Alba-Ruiz R, Jiménez-Pernett J, García Gutiérrez J-F, Traver-Salcedo V, Yubraham-Sánchez D. Use of Social Media by Spanish Hospitals: Perceptions, Difficulties, and Success Factors. Telemed J eHealth 2013;19(2):137-45

11. Lau AYS, Gabarron E, Fernandez-Luque L, Armayones M. Social media in health - what are the safety concerns for health consumers? HIM J 2012;41(2):30-5.

12. Digital Epidemology And Its Ethical, Legal And Social Implications. Berlin (Germany): [publisher unknown] 14-18 September 2015 [cited May 12 2016] Available from: http://www.rki.de/DE/ Content/Service/Veranstaltungen/Delsi_booklet. pdf?_blob=publicationFile

13. Mayer MA, Leis A, Mayer A, Rodriguez-González A. How medical doctors and students should use social media: a review of the main guidelines for proposing practical recommendations. Stud Health 2012;180:853-7.

14. Canadian Medical Association. Social media and Canadian physicians - issues and rules of engagement [Internet]. 2011 [cited 2015 Oct 10]. Available from: www.cma.ca/socialmedia

15. World Medical Association Statement on the professional \& ethical use of social media [Internet]. 2011 Oct [cited 2015 Oct 10]. Available from: http://www.wma.net/en/30publications/10policies/s11/

16. American Medical Association Policy in the use of Social Media [Internet]. 2010 Nov [cited 2015 Oct 10]. Available from: http://www.ama-assn.org/ ama/pub/dab/9124a-abstract.page

17. Australian Medical Association Council and the New Zealand Medical Association [Internet]. 2010 Nov 30 [cited 2015 Oct 10]. Available from: https://ama.com.au/article/social-media-and-medical-profession

18. British Medical Association: Using social media: practical and ethical guidance for doctors and medical students [Internet]. 2013 Oct 21 [cited 2015 Oct 10]. Available from: https://bma.org.uk/-/ media/files/pdfs/practical advice at work/ethics/ socialmediaguidance.pdf

19. Denecke K. Ethical aspects of using medical social media in healthcare applications. Stud Health Technol Inform 2014;198:55-62.

20. Thompson LA, Dawson K. The intersection of online social networking with medical professionalism. J Gen Intern Med 2008;23(7):954-7.

21. MacDonald J, Sohn S, Ellis P. Privacy, professionalism and Facebook: a dilemma for young doctors. Med Educ 2010;44:805-13.

22. Langenfeld SJ, Cook G, Sudbeck C, Luers T, Schenarts PJ. An assessment of unprofessional behaviour among surgical residents on Facebook: a warning of the dangers of social media. J Surg Educ 2014;71(6):e28-32.

23. White J, Kirwan P, Krista L, Walton J, Ross S 'Have you seen what is on Facebook?' The use of social networking software by healthcare professions students. BMJ Open 2103;3:e003013.

24. Chretien KC, Greysen SR, Chretien JP. Online posting of unprofessional content by medical students. JAMA 2009;302:1309-15.

25. Benetoli A, Chen TF, Aslani P. The use of social media in pharmacy practice and education. Res Social Adm Pharm 2015;11(1):1-46.

26. The IMIA Code of Ethics for Health Informatics Professionals. International Medical Informatics Association. [Internet]. [Place unknown]: [publisher unknown]; March 2016 [cited May 12 2016] Available from: http://www.imia-medinfo.org/ new2/pubdocs/Ethics_Eng.pdf

27. von Etter P, Huttunen S, Vihavainen A, Vuorinen M, Yangarber R. Assessment of utility in web mining for the domain of public health. Proceedings of the NAACL HLT 2010 Second Louhi Workshop on Text and Data Mining of Health Documents 2012. p. 29-37.

28. Becker KL. Cyberhugs: creating a voice for chronic pain sufferers through technology. Cyberpsychol Behav Soc Netw 2013;16(2);123-6.

29. de Boer M, Slatman J. Blogging and breast cancer: narrating one's life, body and self on the Internet. Women Stud Int Forum 2014;44(0).

30. Huh J, Liu LS, Neogi T, Inkpen K, Pratt W. Health vlogs as social support for chronic illness management. ACM Trans Comput Hum Interact 2014;21(4).

31. Mo PK, Coulson NS. Online support group use and psychological health for individuals living with HIV/AIDS. Patient Educ Couns 2013;93(3):426-32. 
Hors-Fraile et al.

32. Merolli M, Gray K, Martin-Sanchez F. Therapeutic Affordances of Social Media: Emergent Themes From a Global Online Survey of People With Chronic Pain. J Med Internet Res 2014:16(12):e284.

33. Nordfeldt S, Hanberger L, Berterö C. Patient and Parent Views on a Web 2.0 Diabetes Portal-the Management Tool, the Generator, and the Gatekeeper: Qualitative Study. J Med Internet Res 2010;12(2):e17.

34. Pousti $H$, Burstein F. Barriers of using social media to support health-related decisions: A sociomaterial perspective. Proceedings of the 17th IFIP Working Group 8.3 International Conference on Decision Support Systems, 02 June 2014 to 05 June 2014. Amsterdam Netherlands: IOS Press BV; 2014. p. 545-56.

35. Zebrack B, Isaacson S. Psychosocial care of adolescent and young adult patients with cancer and survivors. J Clin Oncol 2012;30(11):1221-6.

36. Maier-Hein L, Mersmann S, Kondermann D, Bodenstedt S, Sanchez A, Stock C, et al. Can masses of non-experts train highly accurate image classifiers? A crowdsourcing approach to instrument segmentation in laparoscopic images. Med Image Comput Comput Assist Interv 2014;17(Pt 2):438-45.

37. Naroditskiy V, Rahwan I, Cebrian M, Jennings NR. Verification in referral-based crowdsourcing. PLoS One 2012;7(10):e45924.

38. Warrior Eli Hoax Group. Finding The Fakers One At a time [Internet]. [Place unknown]: [publisher unknown]; May 2016 [cited May 04 2016] Available from: http://www.warriorelihoax.com/

39. Childers L. Forbes, Next Avenue [Internet]. [Place unknown]. Childers L. When Medical Bills Pile Up, Can you Crowdfund Your Health Care?; 2013 [cited 2015 October 20]. Available from: http:// www.forbes.com/sites/nextavenue/2013/04/17/ when-medical-bills-pile-up-can-you-crowdfundyour-health-care/

40. Celi LA, Ippolito A, Montgomery RA, Moses C, Stone DJ. Crowdsourcing knowledge discovery and innovations in medicine. J Med Internet Res 2014 Sep 19;16(9):e216.

41. Denecke K, Bamidis P, Bond C, et al. Ethical Issues of Social Media Usage in Healthcare. Yearb Med Inform 2015;10(1):137-47.

42. Lyons EJ, Lewis ZH, Mayrsohn BG, Rowland JL. Behavior Change Techniques Implemented in Electronic Lifestyle Activity Monitors: A Systematic Content Analysis. J Med Internet Res 2014;16(8):e192.

43. Lee Y, Lim Y-K. Understanding the Roles and Influences of Mediators from Multiple Social Channels for Health Behavior Change Proceeding CSCW ' 15 Proceedings of the 18th ACM Conference on Computer Supported Cooperative Work \& Social Computing; 2015. p. 1070-9.

44. Ancker JS, Witteman HO, Hafeez B, Provencher T, Van de Graaf M, Wei E. "You Get Reminded You're a Sick Person": Personal Data Tracking and Patients With Multiple Chronic Conditions. J Med Internet Res 2015;17(8):e202.
45. Hilliard ME, Hahn A, Ridge AK, Eakin MN, Riekert KA. User Preferences and Design Recommendations for an mHealth App to Promote Cystic Fibrosis Self-Management. JMIR mHealth uHealth 2014;2(4):e44.

46. Curtis KE, Lahiri S, Brown KE. Targeting Parents for Childhood Weight Management: Development of a Theory-Driven and User-Centered Healthy Eating App. JMIR mHealth uHealth 2015;3(2):e69.

47. Saksono H, Ranade A, Kamarthi G, Castaneda-Sceppa C, Hoffman JA, Wirth C, et al. Spaceship Launch: Designing a Collaborative Exergame for Families. CSCW ‘15. 2015. p. 1776-87.

48. Walthouwer MJL, Oenema A, Lechner L, de Vries H. Use and Effectiveness of a Video- and Text-Driven Web-Based Computer-Tailored Intervention: Randomized Controlled Trial. J Med Internet Res 2015;17(9):e222.

\author{
Correspondence to: \\ Santiago Hors-Fraile \\ Departamento ATC \\ Escuela Técnica Superior de Ingeniería Informática \\ Universidad de Sevilla \\ 41012 Sevilla, Spain \\ Tel: +34 954556817 \\ E-mail: sanhorfra@gmail.com
}

